\title{
Study on Monitoring Rock Burst through Drill Pipe Torque
}

\author{
Zhonghua Li, Liyuan Zhu, Wanlei Yin, and Yanfang Song
}

Academy of Rock Burst, Liaoning Technical University, Fuxin 123000, China

Correspondence should be addressed to Zhonghua Li; 13941824411@139.com

Received 13 October 2014; Revised 5 January 2015; Accepted 5 January 2015

Academic Editor: Shimin Liu

Copyright (C) 2015 Zhonghua Li et al. This is an open access article distributed under the Creative Commons Attribution License, which permits unrestricted use, distribution, and reproduction in any medium, provided the original work is properly cited.

\begin{abstract}
This paper presents a new method to identify the danger of rock burst from the response of drill pipe torque during drilling process to overcome many defects of the conventional volume of drilled coal rubble method. It is based on the relationship of rock burst with coal stress and coal strength. Through theoretic analysis, the change mechanism of drill pipe torque and the relationship of drill pipe torque with coal stress, coal strength, and drilling speed are investigated. In light of the analysis, a new device for testing drill pipe torque is developed and a series of experiments is performed under different conditions; the results show that drill pipe torque linearly increases with the increase of coal stress and coal strength; the faster the drilling speed, the larger the drill pipe torque, and vice versa. When monitoring rock burst by drill pipe torque method, the index of rock burst is regarded as a function in which coal stress index and coal strength index are principal variables. The results are important for the forecast of rock burst in coal mine.
\end{abstract}

\section{Introduction}

Nowadays, the threat of rock burst is increasingly intensifying with the increase of mining depth and intensity [1-4]. As a result, research on the prediction of rock burst is extremely urgent.

At present, the methods applied to the monitoring of rock burst can be classified into two classes [5-11]: one is geophysical method and the other is geomechanical method. Geophysical methods are circumstantial and use changes in the following physical parameters due to the stress increase in rocks near mine working: acoustic emission, the magnitude of "induced electromagnetic field," and the value of rock selfpotential. However, they are not very mature for their hard equipment maintenance management, high cost, hard data analyzing, and high requirements of technical conditions. At the present time there are no geophysical methods which can completely satisfy the requirements of minimal duration and maximal safety of prediction works [12]. At present the standard geomechanical method of estimating rock burst hazard in coal mines is based on measurement of a volume of "drilled coal rubble" $[13,14]$. Drilling of a borehole leads to excitation of an intensive process of cracking in the zone of its influence. The volume of this zone depends on the hole diameter, the drilling rate, and especially the stress level. If the two first parameters remain constant, the volume of drilled coal rubble formed due to drilling reflects an increase of the third. This method is widely used and already has a set of mature technologies. However, there are also different defects associated with this method; for example, it is not suitable for soft weak coal layer and coal stress crush exceeds the limit; on the other hand, monitoring rock burst by drilled coal rubble method is discontinuous, it is easy to cause loss of information, and both the fly out and residue of drilled coal rubble in the process of drilling can cause drilled coal rubble is not collected incompletely, thereby leading to measurement errors; moreover, the volume of drilled coal rubble has no correlation with coal strength, unable to determine the influence of coal strength on rock burst.

Hence, in this paper, in light of theoretical analysis, the self-designed device is used to test drill pipe torque under different coal stress, coal strength, and drilling speed, respectively, and the method to monitor rock burst by drill pipe torque is presented. The research results provide a new idea for rock burst prediction and have important significance for safety production in coal mine.

\section{Drill Pipe Torque Analysis}

When drilling in coal seam by electric-drill and twist drill pipe, the torque on drill pipe is mainly acted by electric-drill 


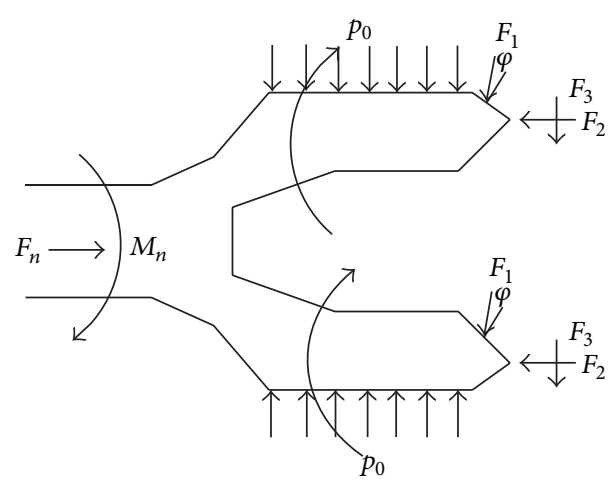

FIGURE 1: External forces of bit.

$\left(M_{0}\right.$, constant under rated power), bit $\left(M_{n}\right)$, and drilled coal rubble $\left(M_{z}\right)[15,16]$. "Drill pipe torque" in this paper refers to the torque in the junction of drill pipe tail end and drilling rig; it is equal to, in numeral, resultant force of $M_{n}$ and $M_{z}$. Then

$$
M_{p}=M_{n}+M_{z}
$$

2.1. Calculation of Torque Applied by Bit. During coal cutting operation, the forces on cutting tool include propulsion $F_{n}$ and cutting force $F_{m}$ acted by drill pipe, anti-cutting resistance $F_{1}$, anti-incisiveness resistance $F_{2}$ acted by coal rock, and frictional resistance $F_{3}$. In addition, there are also pressure $p_{0}$ and friction torque $M_{1}$ acted by hole wall on the side surface of bit, as is shown in Figure 1.

$F_{1}$ is corresponding with the force of coal shear body acted by tool specified in [17] as follows:

$$
F_{1}=P_{1}=\frac{c b h \cos \phi}{\cos (\gamma+\phi+\varphi+\psi) \cos \psi},
$$

where $h$ is cutting depth, $b$ is the width of cutting edge, $c$ is cohesion, $\gamma$ is negative anteversion angle of cutting tool, $\phi$ is internal friction angle, $\varphi=\arctan \mu$ ( $\mu$ is friction coefficient between clearance face and coal face), and $\psi$ is the angle between cutting surface and shear plane. $F_{2}$ is corresponding with the normal pressure acting on the coal by cutting edge. Then

$$
F_{2}=P_{c}=\sigma_{b} S^{\prime},
$$

where $\sigma_{b}$ is coal compressive strength and $S^{\prime}$ is the contacting area of cutting tool with coal. Now let the friction coefficient between cutting edge and coal be $\mu_{1}$; then $F_{3}=\mu_{1} F_{2}$. Let the friction coefficient between coal on hole wall and surface of bit be $\mu_{2}$; then

$$
M_{1}=\mu_{2} \int_{s} p_{0} \cdot R d s=\mu_{2} p_{0} \cdot R s,
$$

where $R$ is radius and $s$ is the contacting area of one side surface of tool with hole wall. Since the bit contains two tools, the torque balance equation of the bit is represented by

$$
M_{n}=2 F_{1} \cos (\gamma+\phi) \cdot R^{\prime}+2 \mu_{1} F_{2} \cdot R^{\prime}+2 M_{1},
$$

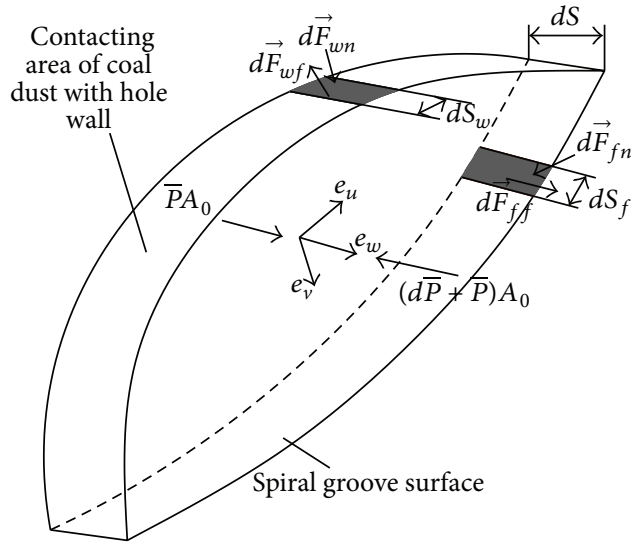

FIGURE 2: Mechanical mode of coal dust element.

where $R^{\prime}$ is the distance between equivalent concentrated force and medial axis of bit. Then, by substituting (2), (3), and (4) into (5), it is found that

$$
\begin{aligned}
M_{n}= & 2 \frac{c b h \cos \varphi}{\cos (\gamma+\varphi+\phi+\psi) \cos \psi} \cos (\gamma+\phi) \cdot R^{\prime} \\
& +2 \mu_{1} \sigma_{b} S^{\prime} \cdot R^{\prime}+2 \mu_{2} p_{0} \cdot R s .
\end{aligned}
$$

2.2. Calculation of Chip Removal Torque. Mechanical analysis of coal dust element drill pipe spiral groove is carried out, gravity and inertia force are neglected, and the external forces of coal dust are generalized as in Figure 2 [15, 18-20]. In Figure 2, $d S_{f}$ denotes the unit width of the interface between coal dust element and the junk slot, $d S$ denotes the thickness of coal dust in the direction of $w, d \vec{F}_{f n}$ and $d \vec{F}_{f f}$ denote the normal force and friction, respectively, which are acted by drill pipe spiral groove, and $d \vec{F}_{w n}, d \vec{F}_{w f}$, and $\bar{P} A_{0}$ denote the normal force, friction, and chip removal force, respectively, which are acted by hole wall on the outside surface of coal dust element.

During coal dust removing operation, the interaction of friction acted by coal wall and normal chip removal force acted by spiral groove results in a distribution of lateral pressure $L$ on coal dust $[17,18,20]$. Then

$$
\begin{gathered}
d \vec{F}_{f n}=L d S_{f} d S \cdot \vec{e}_{f n}, \\
d \vec{F}_{f f}=\mu_{3}\left|d \vec{F}_{f n}\right| \cdot \vec{e}_{f f}=\mu_{3} L d S_{f} d S \cdot \vec{e}_{f f}, \\
d \vec{F}_{w f}=\mu_{4} \cdot d \vec{F}_{w n}=\mu_{4}\left(L d S_{w} \cdot d S \cdot \vec{e}_{\theta}+p_{0} d S_{w} \cdot d S \cdot \vec{e}_{\theta}\right),
\end{gathered}
$$

where $\mu_{3}$ is friction coefficient between coal dust and spiral groove, $\vec{e}_{f n}$ is unit vector in the direction of $d \vec{F}_{f n}$, and $\vec{e}_{f f}$ is unit vector in the direction of $d \vec{F}_{f n}$. [20]

The balance equation of coal dust in the direction of $u$ is

$$
L \Delta v d S-(d L+L) \Delta v d S+d \vec{F}_{w f} \cdot \vec{e}_{u}=0,
$$


where $\Delta v$ is the difference between coal wall and profile of bottom spiral groove in the direction of $v$; it is a function about $u$.

Then, by substituting (8) into (9), it is found that

$$
L(u)=\left(k \bar{P}+p_{0}\right) \alpha e^{u_{4} f(u)}-p_{0},
$$

where $p_{0}$ is the normal pressure acting on drill pipe by coal around borehole, the change block of $u$ coordinate is $\left[u_{a}, u_{b}\right]$, which depends on the geometric parameters of drill pipe, $\mu_{4}$ is the friction coefficient between clearance face and coal face, and $k$ is a coefficient which depends on geometric parameters of drill pipe and drilling speed.

The balance equation of coal dust along the axial line of drill pipe is [20]

$$
\begin{gathered}
\bar{P} A_{0}\left(\vec{e}_{w} \cdot \vec{k}\right)-(d \bar{P}+\bar{P}) A_{0}\left(\vec{e}_{w} \cdot \vec{k}\right) \\
+\int d \vec{F}_{f f} \cdot \vec{k}+\int d \vec{F}_{f n} \cdot \vec{k}=0 .
\end{gathered}
$$

Then, by substituting (7) and (10) into (11), it is found that

$$
\begin{aligned}
\bar{P}= & e^{\int_{0}^{z_{c}}\left(k A E / A_{0}\right) B\left(z_{c}\right) d \eta} \\
& \cdot \int_{0}^{z_{c}} p_{0}\left(z_{c}\right) \frac{E}{A_{0}}\left[A B\left(z_{c}\right)-C\left(z_{c}\right)\right] e^{-\int_{0}^{z_{c}}\left(k A E / A_{0}\right) B\left(z_{c}\right) d \eta} d \eta,
\end{aligned}
$$

where

$$
\begin{gathered}
B\left(z_{c}\right)=\int e^{u_{4} f(u)}\left(\vec{e}_{f n} \cdot \vec{k}\right) d S_{f}+\mu_{3} \int e^{u_{4} f(u)}\left(\vec{e}_{f f} \cdot \vec{k}\right) d S_{f} ; \\
C\left(z_{c}\right)=\int\left(\vec{e}_{f n} \cdot \vec{k}\right) d S_{f}+\mu_{3} \int\left(\vec{e}_{f f} \cdot \vec{k}\right) d S_{f} \\
E=\frac{1}{\left(\vec{e}_{w} \cdot \vec{k}\right) \cos \beta_{h}} .
\end{gathered}
$$

Let drilling depth be $z_{d}$; then the removal force along the axial line of drill pipe is [18]

$$
\vec{F}_{z}\left(z_{d}\right)=2 \bar{P}\left(z_{d}\right) A_{0} \cdot \vec{e}_{w} \cdot \vec{k} .
$$

By substituting (12) into (14) and expanding and rearranging,

$$
\begin{aligned}
F_{z}\left(z_{d}\right)= & 2 A_{0} \cos \beta_{h} e^{\int_{0}^{z_{d}}\left(k \alpha \delta / A_{0}\right) \beta\left(z_{c}\right) d \eta} \\
& \cdot \int_{0}^{z_{d}} p_{0}\left(z_{c}\right) \frac{\gamma}{A_{0}}\left[\alpha \beta\left(z_{c}\right)-\chi\left(z_{c}\right)\right] \\
& \cdot e^{-\int_{0}^{z_{d}}\left(k \alpha \delta / A_{0}\right) \beta\left(z_{c}\right) d \eta} d z_{c} .
\end{aligned}
$$

During drilling operation, the equation of chip removal torque is

$$
M_{z}\left(z_{d}\right)=\left(\vec{r}_{c}\left(z_{d}\right) \times \vec{F}_{w}\left(z_{d}\right)\right) \cdot \vec{k}+\int_{0}^{z_{d}} d M_{w}\left(z_{c}\right),
$$

where $\vec{r}_{c}$ denotes the position vector at the center of coal dust element; $\vec{r}_{c}=R^{\prime} \vec{e}_{r}$.

Now, by substituting (15) into (16) and expanding and rearranging,

$$
M_{z}\left(z_{d}\right)=\bar{P}\left(z_{d}\right) A_{0} \lambda+\psi \int_{0}^{z_{d}} p_{0}\left(z_{c}\right) \gamma d z_{c}+\psi \int_{0}^{z_{d}} k \bar{P} \gamma d z_{c},
$$

where $\lambda\left(z_{d}\right)=A_{0} R^{\prime} \sin \beta_{h} ; \psi=\mu_{4} A R / \cos \beta_{h} ; \gamma\left(z_{c}\right)=$ $\int e^{u_{4} f(u)} d S_{w}$.

2.3. Calculation of Drill Pipe Torque. Then, by substituting (6) and (17) into (1), it can be simplified as

$$
\begin{aligned}
M_{p}= & A_{1} b R^{\prime} h+\sigma_{b} A_{2}+p_{0} A_{3}+\bar{P}\left(z_{d}\right) K\left(z_{d}\right) \\
& +G \int_{0}^{z_{d}} p_{0}\left(z_{c}\right) H d z_{c}+G \int_{0}^{z_{d}} k \bar{P} H d z_{c},
\end{aligned}
$$

where $A_{1}=2(c \cos \phi / \cos (\gamma+\phi+\varphi+\psi) \cos \psi) \cos (\gamma+$ $\varphi), A_{2}=2 \mu_{1} S^{\prime} R^{\prime}$, and $A_{3}=2 \mu_{2} R s_{2} . \bar{P}$ increases with the increase of coal stress, $A_{1}$ increases with the increase of coal strength, both $b$ and $h$ increase with the increase of drilling speed, $S^{\prime}, A_{2}$, and $A_{3}$ all have something to do with geometric parameters of bit, and $K, G$, and $H$ all have something to do with geometric parameters of drill pipe.

\section{Principle of Monitoring Rock Burst by Drill Pipe Torque Method}

A degree of rock burst is inevitably associated both with the stress level near mine working and with the strength of coal. There is precursor information of stress concentration (high stress) and mutation (high stress mutation) in local area before rock burst $[21,22]$. Therefore, the stress is reliable for monitoring rock burst; monitoring means such as $\mathrm{AE}$ method and volume of drilled coal rubble method reflect coal stress state through certain physical quantity and then judge rock burst risk based on stress trend. Coal strength is an important mechanical character parameter and also a significant indicator of coal seam burst tendency judgment. Coal strength and its variation have a great influence on rock burst hazard. The change of stress in the laneway periphery with the increase of mining depth is different depending on the compressive strength of coal rock mass; if covered depth exceeds the critical depth, coal mass will meet various degrees of violation; it provides condition for occurrence of rock burst. The larger the compressive strength and the sustained forces before failure, the larger the elastic energy accumulated in coal mass; then it is much easier to induce rock burst.

Based on the relationship of rock burst with coal stress and coal strength, monitoring rock burst by drill pipe torque method is designed. It can be known from the calculation results of Section 2 that there is a positive correlation of drill pipe torque and coal stress and coal strength in the course of drilling, if the drilling equipment and drilling speed are constant. Thus, when drilling with constant speed, coal stress and coal strength can be reflected by drill pipe torque, and 
TABLE 1: Loading and drilling conditions of the samples.

\begin{tabular}{|c|c|c|c|c|c|c|}
\hline $\begin{array}{l}\text { Sample } \\
\text { number }\end{array}$ & $\begin{array}{c}\text { Loading } \\
\text { pressure/kN }\end{array}$ & Coal stress/MPa & Coal strength/MPa & Drilling speed $/ \mathrm{m} / \mathrm{min}$ & Drilling time/s & Drilling depth/mm \\
\hline 1 & 1500 & 6.0 & 15 & 0.22 & 120 & 440 \\
\hline 2 & 2000 & 8.0 & 15 & 0.22 & 120 & 440 \\
\hline 3 & 2500 & 10.0 & 15 & 0.22 & 120 & 440 \\
\hline 4 & 3000 & 12.0 & 15 & 0.22 & 120 & 440 \\
\hline 5 & 3500 & 14.0 & 15 & 0.22 & 120 & 440 \\
\hline 6 & 2500 & 10.0 & 7 & 0.4 & 60 & 400 \\
\hline 7 & 2500 & 10.0 & 10 & 0.4 & 60 & 400 \\
\hline 8 & 2500 & 10.0 & 15 & 0.4 & 60 & 400 \\
\hline 9 & 2500 & 10.0 & 19 & 0.4 & 60 & 400 \\
\hline 10 & 2500 & 10.0 & 24 & 0.4 & 60 & 400 \\
\hline 11 & 2500 & 10.0 & 15 & 0.15 & 192 & 480 \\
\hline 12 & 2500 & 10.0 & 15 & 0.2 & 144 & 480 \\
\hline 13 & 2500 & 10.0 & 15 & 0.3 & 96 & 480 \\
\hline
\end{tabular}

then quantitative relation of drill pipe torque with coal stress and coal strength is established and rock burst hazard is judged; the goal of forecasting rock burst is achieved.

\section{Drill Pipe Torque Experiments}

4.1. Experiments Device. The test system consists of drilling equipment, test device of torque, data acquisition and recording system, and other assistive devices (Figure 3). Drilling equipment includes $1.2 \mathrm{kw}$ hand-held electric coal drill, $\phi$ 42 hollow twist drill rods, and bit; test device of torque is the central unit of the test system, which is independently developed with a torque sensor mounted at the output terminal of electric coal drill. It can be continuously used to measure a real-time torque. YJZ-8/16 type digital strain gauge is chosen as the data acquisition and recording device, and results can be displayed on computers.

4.2. Experiments Scheme. Large size coal specimens collected from scene were put into iron cases which have dimension of $500 \mathrm{~mm} \times 500 \mathrm{~mm} \times 500 \mathrm{~mm}$ and thickness of $30 \mathrm{~mm}$, and the surrounding areas were packed with cement mortar. The backs of specimens were pasted on the inner lining of the iron cases. Thus, the distortion in this direction was limited under force. The space exists between the left and right sides of the samples and iron cases were packed with S588 sealing colloid. It has little effect on lateral deformation of coal under force, since S-588 colloid is elastic after solidifying. This allowed the acting form of the samples to be similar to that of coal body ahead of mining face; then coal stress ahead of mining face was simulated through pressuring the samples vertically.

13 specimens were made in all; among them, samples $1 \sim 5$ were used to study the relationship between drill pipe torque and coal stress; in this experiment, drilled coal rubble was collected while drilling and was weighed after drilling; samples 6 10 were used to study the relationship between coal strength and drill pipe torque; samples $11 \sim 13$ were used to study the influence of drilling speed on drill pipe torque. The loading and drilling conditions of the samples are listed in Table 1.

When testing, the torque sensor was mounted on the junction of drill pipe tail end and drilling rig; wires were leaded out by rotary joint connected to the data acquisition device connected to computer. To keep the electric-drill running horizontally and uniformly in drilling process, the electric-drill was mounted on the self-designed support with scales on its horizontal guide; it controlled drilling speed constant combined with timer during the drilling operation. In order to make the stress of the specimens uniform, a $500 \mathrm{~mm} \times 500 \mathrm{~mm} \times 15 \mathrm{~mm}$ plate was put on the upper surface of the specimen, and a cushion block was put on the plate. The data acquisition and recording system was booted to acquire and record test data synchronously and automatically, testing machine was booted to pressure the specimens according to the test conditions, and electric-drill was booted to drill at the reference speed combined with stopwatch. When the procedure finished, data acquisition was stopped and then the testing machine was turned off.

\subsection{Analysis of Experiments Results}

4.3.1. Relationship between Drill Pipe Torque and Coal Stress. The change curve of drill pipe under different coal stress during drilling operating is obtained from the results of the recording (Figure 4). As it can be seen in Figure 4, under the same drilling speed, drill pipe torque under different coal stress fluctuates in a certain magnitude due to factors such as cracks and shake, but analyzing the entire tendency, the larger the coal stress, the larger the drill pipe torque.

The practice of prediction of mine dynamic disaster shows that coal stress can be reflected by volume of drilled coal rubble. When coal stress increases, the risk of rock burst increases and the volume of drilled coal rubble also increased. In order to verify that the magnitude and variation regularity of the coal stress can be reflected by drill pipe 


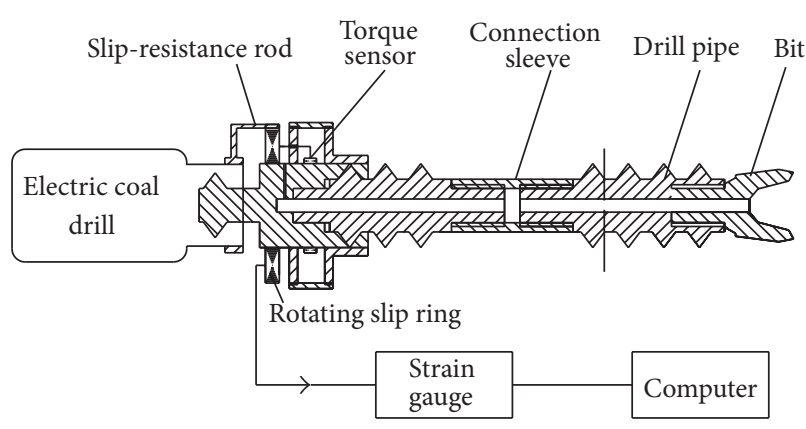

(a)

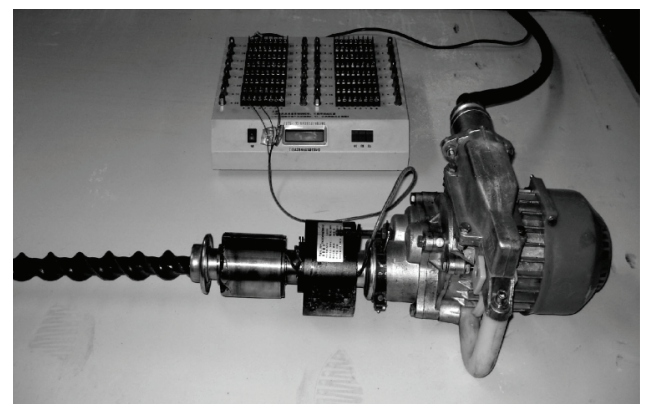

(b)

FIGURE 3: Drill pipe torque test equipment.

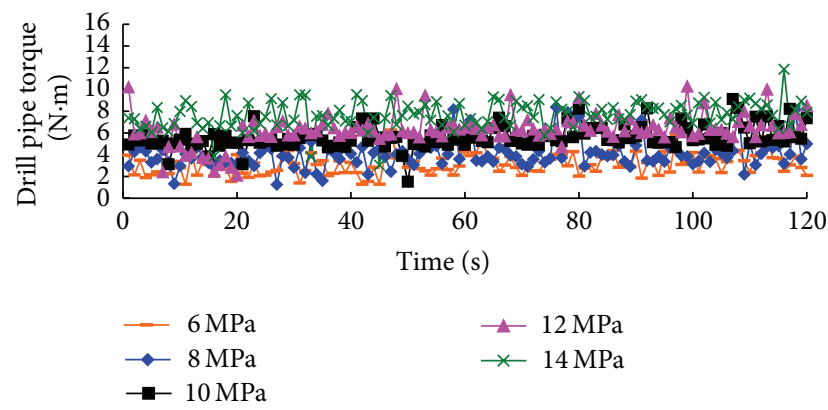

FIGURE 4: History time curve of drill pipe torque under different coal stress.

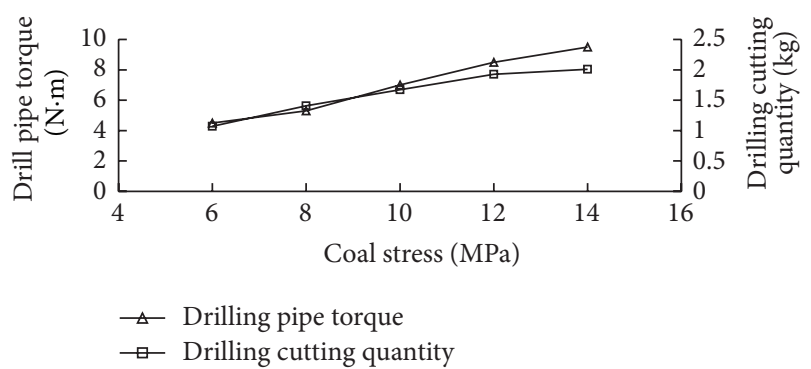

FIGURE 5: The comparison of drill pipe torque, volume of drilled coal rubble, and coal stress.

torque further, the relationship of coal stress with volume of drilled coal rubble and drill pipe torque was comparatively analyzed (Figure 5). As it can be seen in Figure 5, drill pipe torque had a similar changing trend to the volume of drilled coal rubble. We also fit the curve and gain the fitting relation of coal stress with volume of drilled coal rubble and drill pipe torque:

$$
\begin{gathered}
M_{p}=0.66 \sigma+0.36, \quad\left(R^{2}=0.9882\right), \\
G_{0}=0.1199 \sigma+0.4195, \quad\left(R^{2}=0.9648\right),
\end{gathered}
$$

where $M_{p}$ is drill pipe torque and $\sigma$ is coal stress; $G_{0}$ is volume of drilled coal rubble.

Thus, it can be seen that both volume of drilled coal rubble and drill pipe torque linearly increase with the increase of

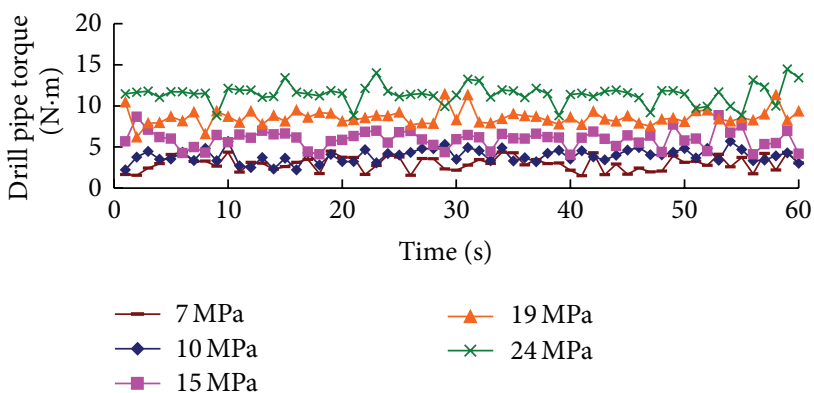

Figure 6: Time history curve of drill pipe torque under different coal strength.

coal stress, and they have good correspondences. It indicates that drill pipe torque can reflect the magnitude and variation regularity of the coal stress and then monitor rock burst.

4.3.2. Relationship between Drill Pipe Torque and Coal Strength. Outcome of drill pipe torque under different coal strength is presented in Figure 6. As it can be seen in Figure 6, coal strength has significant effect on drill pipe torque though with a little fluctuation in it. Under the same coal stress and drilling speed, the larger the coal strength, the larger the drill pipe torque.

During the drilling process, when coal strength is $7 \mathrm{MPa}$, average value of drill pipe torque is $3.28 \mathrm{~N} \cdot \mathrm{m}$; when coal strength is $10 \mathrm{MPa}$, average value of drill pipe torque is $4.30 \mathrm{~N} \cdot \mathrm{m}$; when coal strength is $15 \mathrm{MPa}$, average value of drill pipe torque is $6.75 \mathrm{~N} \cdot \mathrm{m}$; when coal strength is $19 \mathrm{MPa}$, average value of drill pipe torque is $7.25 \mathrm{~N} \cdot \mathrm{m}$; when coal strength is $24 \mathrm{MPa}$, average value of drill pipe torque is $10.86 \mathrm{~N} \cdot \mathrm{m}$. Outcome of regression analysis is presented in Figure 7. As it can be seen in Figure 7, drill pipe torque linearly increases with the increase of coal strength; they have good interrelations; the curve relation of them is

$$
M_{p}=0.4306 \sigma_{c}+0.0822, \quad\left(R^{2}=0.9763\right),
$$

where $\sigma_{c}$ is coal strength.

4.3.3. Influence of Drilling Speed on Drill Pipe Torque. Taking time as the abscissa axis and drill pipe torque as the ordinate 


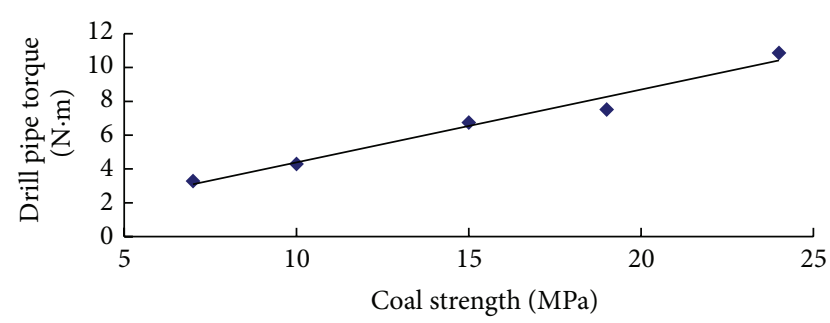

Figure 7: The curve relation between drill pipe torque and coal strength.

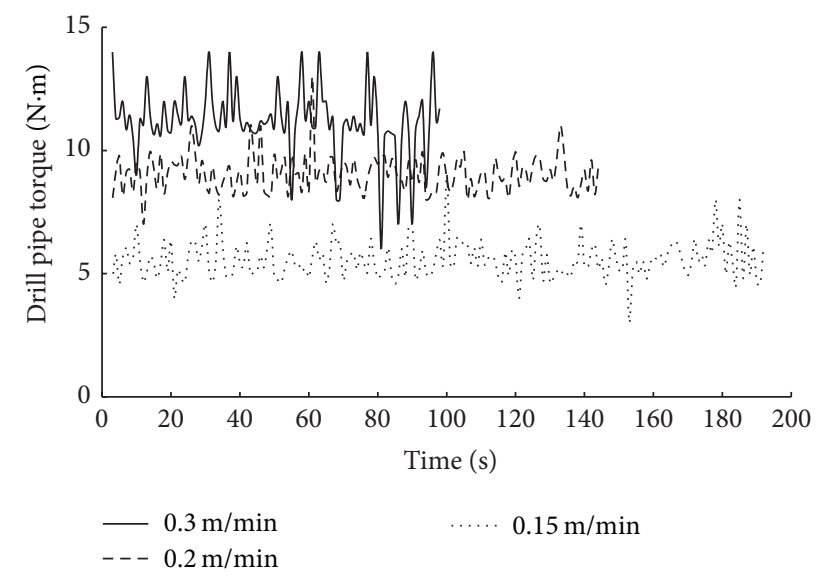

Figure 8: History time curve of drill pipe torque under different drilling speed.

axis, the curve relation between drill pipe torque and drilling time under different drilling speed was obtained (Figure 8).

As it can be seen in Figure 8, for the same material and pressure, drill pipe torques tested under different drilling speed have a great difference: when drilling speed is $0.15 \mathrm{~m} / \mathrm{min}$, average value of drill pipe torque is $5.21 \mathrm{~N} \cdot \mathrm{m}$; when drilling speed is $0.20 \mathrm{~m} / \mathrm{min}$, average value of drill pipe torque is $8.44 \mathrm{~N} \cdot \mathrm{m}$; when drilling speed is $0.30 \mathrm{~m} / \mathrm{min}$, average value of drill pipe torque is $10.16 \mathrm{~N} \cdot \mathrm{m}$.

Therefore, drilling speed should be strictly controlled and should always keep pace while monitoring rock burst by drill pipe torque method.

\section{Monitoring Rock Burst by Drill Pipe Torque Method}

In order to determine the possibility of rock burst occurrence quantitatively, the paper regards the index of rock burst $I$ as a function in which coal stress index $I_{s}$ and coal strength index $I_{c}$ are principal variables; namely, the index of rock burst can be expressed as

$$
I=f\left(I_{s}, I_{c}\right),
$$

where $I_{s}$ is the membership degree of judging the danger of rock burst by coal stress and $I_{c}$ is the membership degree of judging the danger of rock burst by coal strength.
5.1. Determination of Coal Stress Index $I_{s}$. As the high stress concentration and mutation are essential conditions of rock burst, coal stress varies in a greater range for a period of time before rock burst occurrence, and the studies in previous paper have proved that there exists a close relationship between coal stress and drill pipe torque. Therefore, coal changes can be reflected through drill pipe torque and then forecast rock burst.

The procedure of determining coal stress index $I_{s}$ is carried out as follows: when the drill pipe torque at a certain depth reached or exceeded the forecasting and warning value $M_{0}$ ( $M_{0}$ depends on conditions of workface), taking the moment as starting point, work out increment amplitude of drill pipe torque in interval time and then determine coal stress index $I_{s}$ by increment amplitude of drill pipe torque. The relationship between coal stress index $I_{s}$ and increment amplitude of drill pipe torque is

$$
\begin{gathered}
\Delta M=\frac{M\left(t_{n}\right)-M\left(t_{n-1}\right)}{M\left(t_{n-1}\right)}, \\
I_{s}= \begin{cases}\frac{\Delta M}{\gamma_{0}}, & \left(0<\Delta M\left(t_{n}\right)<\gamma_{0}\right), \\
1, & \left(\Delta M\left(t_{n}\right) \geq \gamma_{0}\right),\end{cases}
\end{gathered}
$$

where $t_{n}=n t_{0}, M\left(t_{n}\right)$ is the drill pipe torque at the moment of $t_{n}, \gamma_{0}$ is the critical value of increment amplitude of drill pipe torque (the value of $\gamma_{0}$ can be modified according to field condition), and $n$ is integer.

5.2. Determination of Coal Strength Index $I_{c}$. As coal strength is a major factor of rock burst, it is reasonable to judge the probability of rock burst by coal strength; the judgment formula is

$$
C_{0}= \begin{cases}\frac{\sigma}{\sigma_{0}}, & \left(\sigma<\sigma_{0}\right), \\ 1, & \left(\sigma \geq \sigma_{0}\right)\end{cases}
$$

where $\sigma$ is strength of bored coal and $\sigma_{0}$ is strength critical value of rock burst forecast. In terms of the expression for relationship between drill pipe torque and coal strength in Section 4.3.2, different coal strengths correspond to different drill pipe torques; it is then possible to get coal strength index by the simplified equation (23):

$$
I_{c}= \begin{cases}\frac{M}{M_{0}}, & \left(M<M_{0}\right), \\ 1, & \left(M \geq M_{0}\right),\end{cases}
$$

where $M$ is drill pipe torque measured by drilling (average value) and $M_{0}$ is forecast critical value for judging coal stress by drill pipe torque. When the drill pipe torque is greater than or equal to critical value, the probability of rock burst occurrence is considered to be 1 ; when the drill pipe torque is less than critical value, coal strength index $I_{c}$ is a linear function which takes the reciprocal of drill pipe torque forecast critical value as slope and drill pipe torque as variable. 
TABLE 2: The possibility of evaluation index of the rock burst occurrence evaluated by the drill pipe torque method.

\begin{tabular}{lcccc}
\hline Possibility of rock burst occurrence & Impossible & Possible & Probably & Extremely large possibility \\
\hline Evaluation indictor $I$ & $0 \sim 0.4$ & $0.4 \sim 0.6$ & $0.6 \sim 0.8$ & $0.8 \sim 1.0$ \\
\hline
\end{tabular}

5.3. Determination of Rock Burst Index I. After coal stress index $I_{s}$ and coal strength index $I_{c}$ are determined, index $I$ that monitors rock burst by drill pipe torque method can be expressed as

$$
I=a I_{s}+b I_{c},
$$

where $a$ and $b$ are, respectively, the weights for $I_{s}$ and $I_{c}$ in prediction of rock burst, different mining condition endows different weights for $a, b$, and the sum of $a, b$ is 1 . Based on the value of $I$ rock burst index can be divided into 4 classes of impossible, possible, probably, and extremely large possibility; they are relative to the possibility of the impact rock pressure occurrence, as shown in Table 2. Due to the high difference on geological, mining conditions and complicated reasons of rock burst, the evaluation indexes put forward in this paper need to be further modified and perfected.

\section{Conclusion}

In this paper, the authors make a test research with the independently developed system on characteristics of drill pipe torque under different coal stress, coal strength, and drilling speed on the basis of theoretical analysis and illustrate how to monitor rock burst through drill pipe torque. The major conclusions are as follows.

(1) Through theoretic analysis, the formula for calculating drill pipe torque was derived, the conclusion that drill pipe torque can reflect coal stress and coal strength and is influenced by drilling speed was drawn, and the principle of monitoring rock burst by drill pipe torque was revealed.

(2) The results of experiments show that drill pipe torque linearly increases with the increase of coal stress and coal strength; the faster the drilling speed, the larger the drill pipe torque, and vice versa.

(3) While monitoring rock burst by drill pipe torque method, coal stress factor and coal strength factor are comprehensively considered; drill pipe torque method is simple and convenient, can realize realtime and continuous monitoring, and can overcome the defects of volume of drilled coal rubble method. The indicator of drill pipe torque can be tested in the same hole with indicators such as drilled coal rubble and can reach the goal of multiobjective prediction; it is a promising method of rock burst prediction.

Drill pipe torque method is a new rock burst prediction method; present studies on it are not satisfactory; this paper investigates it only from theoretical and laboratory experiment aspects. Future work should involve locale experiments to determine its critical index; furthermore, more complex experimental systems should be investigated.

\section{Conflict of Interests}

The authors declare that there is no conflict of interests regarding the publication of this paper.

\section{Acknowledgments}

The authors would like to acknowledge the financial support of National Natural Science Foundation of China (Grant no. 51174107) and National Program on Key Basic Research Project (Grant no. 2010CB0226803).

\section{References}

[1] T. Li, M. F. Cai, and M. Cai, "A review of mining-induced seismicity in China," International Journal of Rock Mechanics and Mining Sciences, vol. 44, no. 8, pp. 1149-1171, 2007.

[2] V. S. Kuksenko, I. E. Inzhevatkin, B. T. Manzhikov, S. A. Stanchits, N. G. Tomilin, and D. I. Frolov, "Physical and methodological principles of rock burst prediction," Soviet Mining, vol. 23, no. 1, pp. 6-17, 1987.

[3] Z. T. Bieniawski, H. G. Denkhaus, and U. W. Vogler, "Failure of fractured rock," International Journal of Rock Mechanics and Mining Sciences and, vol. 6, no. 3, pp. 323-341, 1969.

[4] N. G. W. Cook, "A note on rockbursts considered as a problem of stability," The Southern African Institute of Mining and Metallurgy, vol. 65, pp. 437-446, 1965.

[5] J. P. Bardet, "Finite element analysis of rockburst as surface instability," Computers and Geotechnics, vol. 8, no. 3, pp. 177-193, 1989.

[6] H. Wang and M. Ge, "Acoustic emission/microseismic source location analysis for a limestone mine exhibiting high horizontal stresses," International Journal of Rock Mechanics and Mining Sciences, vol. 45, no. 5, pp. 720-728, 2008.

[7] M. Ge, "Efficient mine microseismic monitoring," International Journal of Coal Geology, vol. 64, no. 1-2, pp. 44-56, 2005.

[8] P. R. Young, Rock Bursts Andseismicity in Mines, Balkema, Rotterdam, The Netherlands, 1993.

[9] A. Leśniak and Z. Isakqw, "Space-time clustering of seismic events and hazard assessment in the Zabrze-Bielszowice coal mine, Poland," International Journal of Rock Mechanics and Mining Sciences, vol. 46, no. 5, pp. 918-928, 2009.

[10] V. A. Mansurov, "Prediction of rockbursts by analysis of induced seismicity data," International Journal of Rock Mechanics and Mining Sciences, vol. 38, no. 6, pp. 893-901, 2001.

[11] J.-A. Wang and H. D. Park, "Comprehensive prediction of rockburst based on analysis of strain energy in rocks," Tunnelling and Underground Space Technology, vol. 16, no. 1, pp. 49-57, 2001.

[12] V. Frid, "Rockburst hazard forecast by electromagnetic radiation excited by rock fracture," Rock Mechanics and Rock Engineering, vol. 30, no. 4, pp. 229-236, 1997.

[13] B. J. Zhao and M. T. Zhang, "The study and application of the drilling method," Journal of Fuxin Mining Institute, vol. S1, pp. 13-28, 1985 (Chinese). 
[14] C. G. Wen and Y. X. Wang, "Discussion of value of drilling cuttings weight index," Journal of Mining Safety and Environment Protection, vol. 3, p. 32, 1998.

[15] J. C. Mellinger, O. B. Ozdoganlar, R. E. Decor, and S. G. Kapoor, "Modeling chip-evacuation forces and prediction of chip-clogging in drilling," Journal of Manufacturing Science and Engineering, vol. 124, no. 3, pp. 605-614, 2002.

[16] J. C. Mellinger, O. B. Ozdoganlar, R. E. DeVor, and S. G. Kapoor, "Modeling chip-evacuation forces in drilling for various flute geometries," Journal of Manufacturing Science and Engineering, Transactions of the ASME, vol. 125, no. 3, pp. 405-415, 2003.

[17] F. Zhao, Theoretical and experimental research on rock fragmentation under coupling dynamic and static loads [Ph.D. thesis], Central South University, 2004 (Chinese).

[18] Q. Yu and G.-H. Hu, "Development of a helical coordinate system and its application to analysis of polymer flow in screw extruders part I. The balance equations in a helical coordinate system," Journal of Non-Newtonian Fluid Mechanics, vol. 69, no. 2-3, pp. 155-167, 1997.

[19] K. Ren and J. Ni, "Analyses of drill flute and cutting angles," The International Journal of Advanced Manufacturing Technology, vol. 15, no. 8, pp. 546-553, 1999.

[20] X. Wan, Study on new drilling force model of vibration drilling and vibration drilling with invariable parameter and variable parameter [Ph.D. thesis], Jilin University, 2004, (Chinese).

[21] B. Amadei and O. Stephansson, Rock Stress and Its Measurement, Chapman \& Hall, London, UK, 1997.

[22] J. Franklin, "Suggested methods for pressure monitoring using hydraulic cells," International Journal of Rock Mechanics and Mining Sciences \& Geomechanics Abstracts, vol. 17, no. 2, pp. 117127, 1980. 

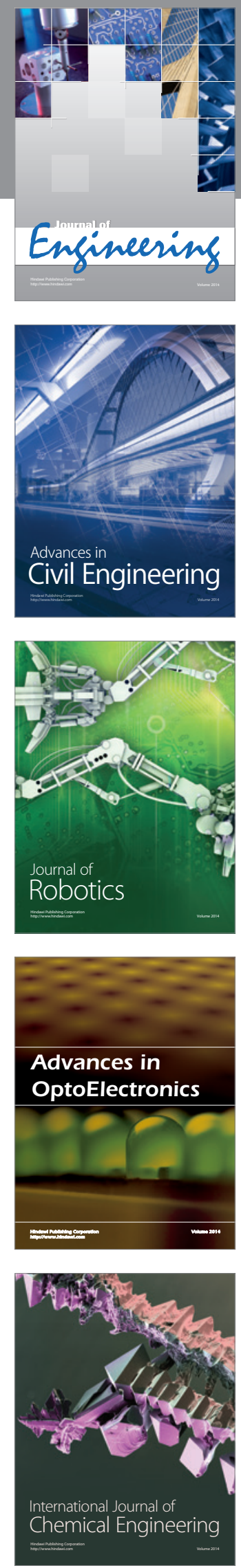

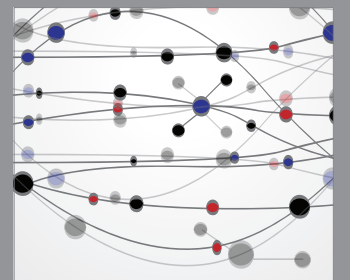

The Scientific World Journal
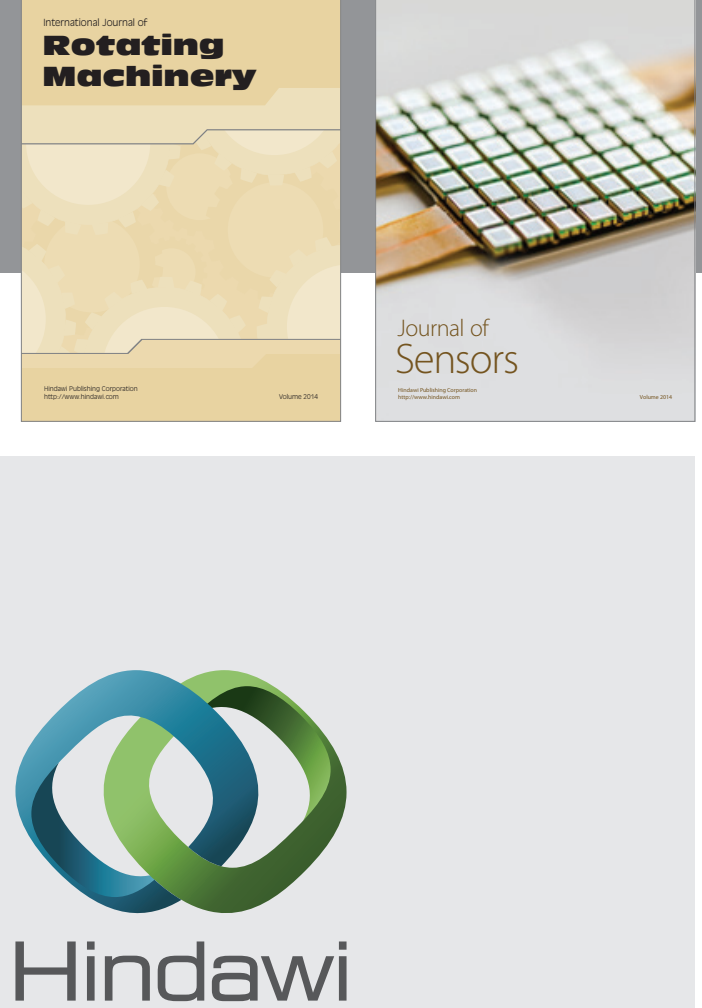

Submit your manuscripts at http://www.hindawi.com
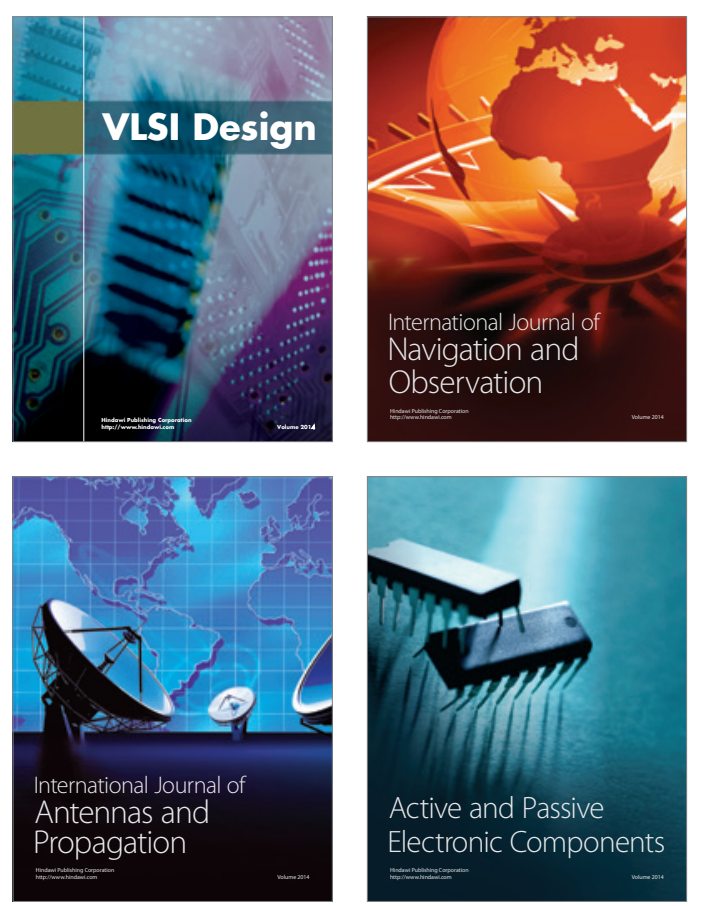
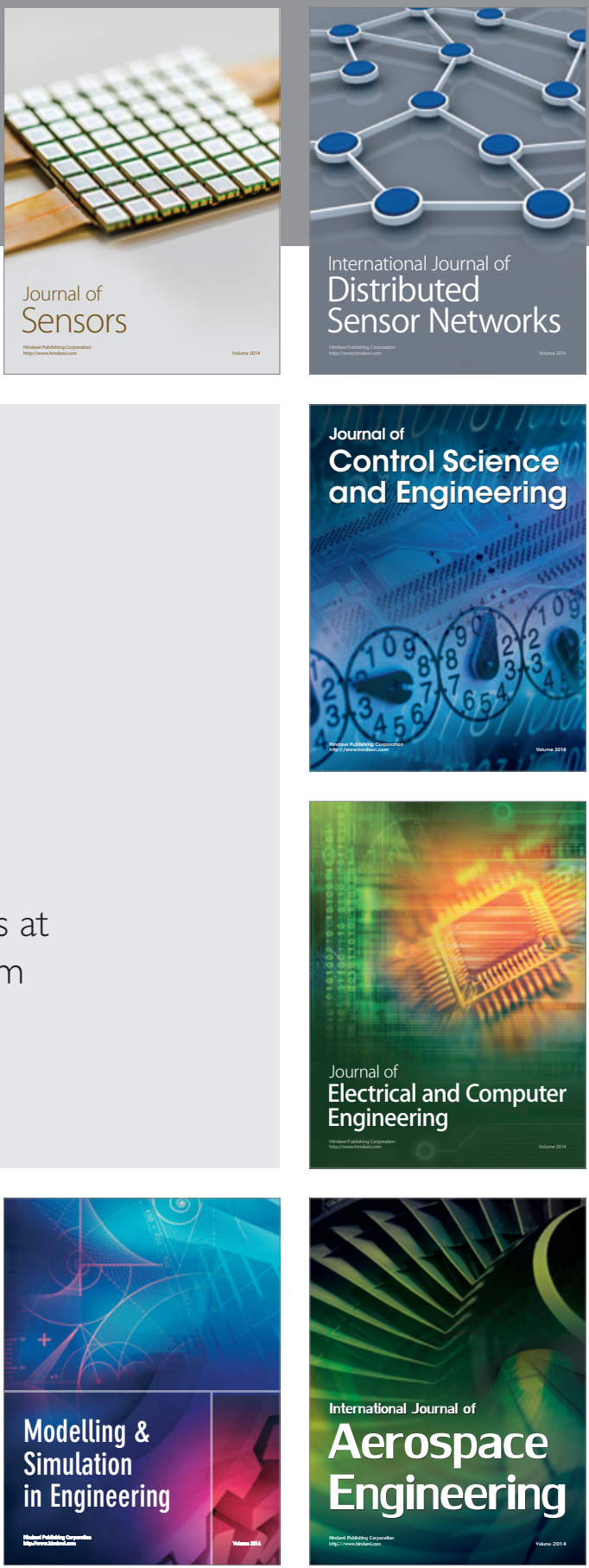

Journal of

Control Science

and Engineering
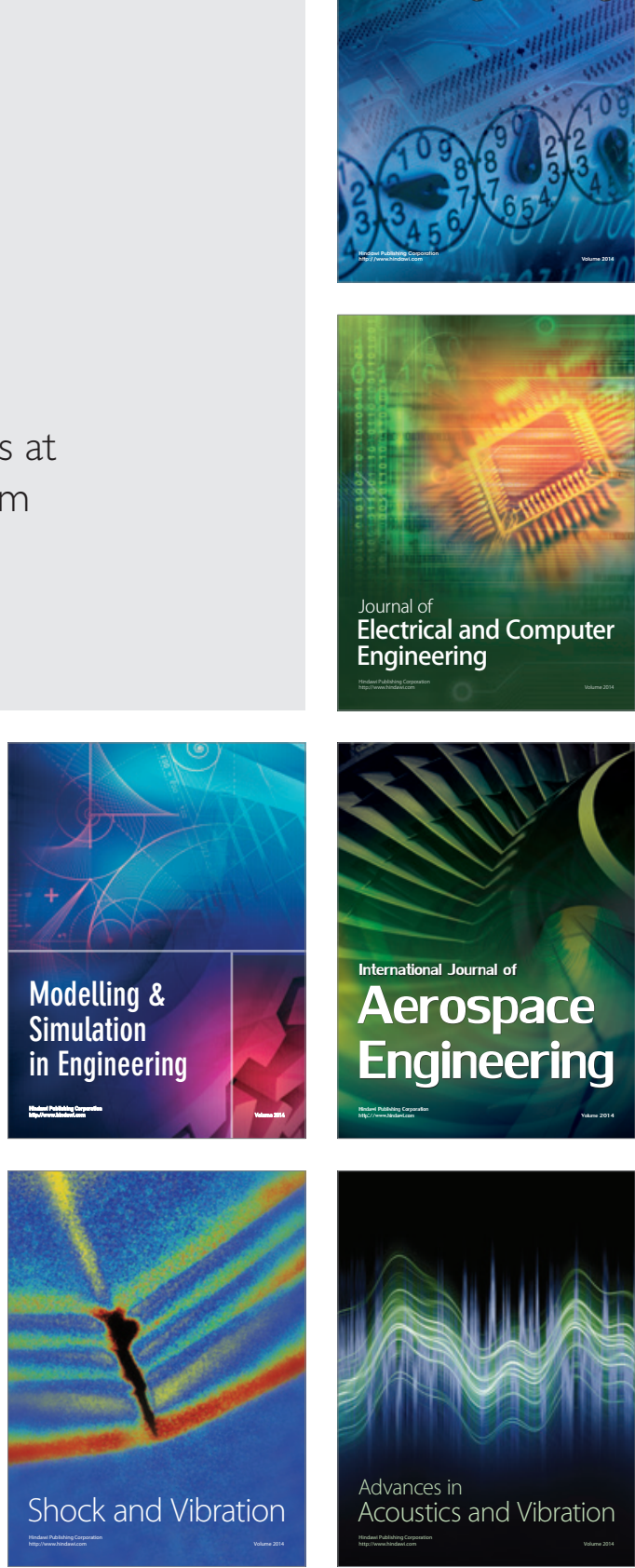